\title{
Corea gravídica asociada a lupus eritematoso sistémico y síndrome antifosfolípido: reporte de caso
}

\author{
Chorea gravidarum associated with systemic lupus erythematosus and antiphospholipid \\ syndrome: case report
}

\author{
Laura E. Godínez-Baca, Gustavo E. Lugo-Zamudio* y Lucía V. Maya-Piña
}

Servicio de Reumatología, Hospital Juárez de México, Ciudad de México, México

\begin{abstract}
Resumen
Las manifestaciones neuropsiquiátricas en los pacientes con lupus eritematoso sistémico (LES) y síndrome antifosfolípido (SAF) secundario son muy frecuentes. En ambos casos, la fisiopatología se correlaciona con vasculopatía asociada a anticuerpos antifosfolípido y neurotoxicidad por anticuerpos y citocinas. La corea es el único trastorno del movimiento incluido en los 19 síndromes neuropsiquiátricos del LES según el American College of Rheumatology, con presentación inusual (prevalencia del 2\%), y puede ocurrir como primera manifestación de la enfermedad. Se describe el caso de una paciente de 17 años con corea desencadenada durante el embarazo como manifestación inicial de LES y SAF.
\end{abstract}

Palabras Clave: Corea. Lupus eritematoso sistémico. Manifestaciones neuropsiquiátricas. Síndrome antifosfolípido.

\begin{abstract}
Neuropsychiatric symptoms of systemic lupus erythematosus (SLE) and secondary antiphospholipid syndrome (APS) are very common. In both cases, pathophysiology is

correlated to vasculopathy associated to antiphospholipid antibodies as well as neurotoxicity mediated by antibodies and cytokines. Chorea, instead, is the only movement disorder included in the 19 SLE's neuropsychiatric syndromes described by the American College of Rheumatology. Nevertheless, its presence is unusual with a prevalence of about $2 \%$, and could appear as an early manifestation of the disease. The case of a 17-year-old pregnant woman in whom chorea was an early manifestation of SLE and APS.
\end{abstract}

Key Words: Chorea. Systemic lupus erythematosus. Neuropsychiatric manifestations. Antiphospholipid syndrome.

\section{Introducción}

Las manifestaciones neurológicas en el lupus eritematoso sistémico (LES) y el síndrome antifosfolípido (SAF) son frecuentes y pueden involucrar al sistema nervioso central y periférico'. En los pacientes con LES tienen una prevalencia del 56\%. En 1999, el American College of Rheumatology describió 19 síndromes neuropsiquiátricos, entre los cuales se incluyó la corea como el único trastorno del movimiento2-5. En

\section{Correspondencia:}

*Gustavo E. Lugo-Zamudio

Avda. Instituto Politécnico Nacional, 5160

Col. Magdalena de las Salinas, Alcaldía Gustavo A. Madero

C.P. 06770, Ciudad de México, México

Fecha de recepción: 15-08-2019

Fecha de aceptación: 06-11-2019

E-mail: gelz1@prodigy.net.mx
Cir Cir. 2020;88(S1):59-62 Contents available at PubMed www.cirugiaycirujanos.com (http://creativecommons.org/licenses/by-nc-nd/4.0/). 
Ios pacientes con LES, las alteraciones del movimiento se reportan en el $0.9 \%$ y la más común es la corea, con una prevalencia del $2 \%$. En cambio, en el SAF la prevalencia de la corea es del $1.3 \%{ }^{5}$.

El mecanismo fisiopatológico preciso se desconoce, pero los reportes previos han identificado la presencia de anticuerpos antifosfolípido en el $92 \%$ de los pacientes con LES y corea ${ }^{5}$, por lo que se propone que dichos anticuerpos cruzan la barrera hematoencefálica y provocan neurotoxicidad por mecanismos adicionales a la vasculopatía y la hipercoagulabilidad (Tabla 1).

La corea se distingue por movimientos involuntarios abruptos, irregulares, bruscos e impredecibles que dan la apariencia de recorrer una parte del cuerpo a otra. La disartria, los cambios de personalidad y del estado de ánimo, y el déficit cognitivo pueden ser signos y síntomas acompañantes. Los estudios de imagen por lo general resultan normales; sin embargo, la tomografía por emisión de positrones, aunque no se recomienda sistemáticamente, puede mostrar hipermetabolismo en el núcleo estriado. En el caso de la tomografía computarizada por emisión de fotón único, se identifica un aumento del flujo talámico. El tratamiento debe ir dirigido a la causa subyacente y a los síntomas. Los neurolépticos bloqueadores de los receptores de dopamina y las benzodiacepinas son eficaces para controlar los movimientos involuntarios, y los glucocorticoides, los inmunosupresores y los anticoagulantes son efectivos para el tratamiento del LES y el SAF'.

En algunos casos, la corea puede aparecer de forma aislada durante el embarazo y entonces se denomina corea gravídica, con una incidencia de 1 por cada 2,275 embarazos. Suele resolverse durante el tercer trimestre de gestación o al finalizarla 7 , lo que sugiere que el estado hiperestrogénico participa en la hipersensibilidad a la dopamina, aumentando su síntesis y su liberación a nivel estriatal y de los ganglios basales. Por su presentación indistinguible clínicamente de otras causas de corea, la evaluación de estas pacientes debe ser extensa y multidisciplinaria.

En 1980, Ichikawa, et al. ${ }^{8}$ agregaron el reporte de un caso de corea gravídica a los 10 casos descritos previamente desde 1906, correspondiente a una paciente primigesta de 23 años que a las 39 semanas de gestación presentó corea gravídica, con fallecimiento del binomio.

Por lo general, el pronóstico suele ser bueno, aunque la recurrencia se presenta en embarazos posteriores $^{9}$ y la mortalidad materna es del $1 \%{ }^{10}$.
Tabla 1. Mecanismos patogénicos potenciales de los anticuerpos antifosfolípido en el sistema nervioso

- Alteración en la expresión de moléculas de adhesión, óxido nítrico y factor tisular, que provocan disfunción endotelial y aumento de la permeabilidad de la barrera hematoencefálica.

- La unión al complejo de membrana $\beta 2-G P 1$ provoca activación del factor nuclear kappa B y disfunción celular.

- Formación acelerada de placas de amiloide y activación de la microglía.

- Disminución del umbral neutoróxico del glutamato.

- Aumento en la producción de factor de necrosis tumoral y de prostaglandinas.

Adaptada de Baizabal-Carvallo, et al. ${ }^{5}$

\section{Caso clínico}

Paciente femenino de 17 años con único antecedente patológico de aborto espontáneo en el primer trimestre, con secunda gesta de 19 semanas en adecuado control prenatal. Acudió a urgencias de ginecología y obstetricia por cuadro clínico de 1 mes de evolución caracterizado por agresividad, insomnio, desorientación, disartria y movimientos coreicos incapacitantes. Durante la exploración física se encontró alerta, irritable, con dislalia, disartria, alteraciones de la memoria y de cálculo; se describen además movimientos bruscos, involuntarios e irregulares en la cara, los brazos y las piernas. No se observan alteraciones cardiacas ni pulmonares. El abdomen se observó globoso a expensas de útero gestante, con fondo uterino de $18 \mathrm{~cm}$, feto único, vivo, con una frecuencia cardiaca de 140 latidos por minuto, sin actividad uterina y con adecuada vitalidad del producto documentada por ultrasonido obstétrico. Fue valorada por los servicios de toxicología y neurología, que descartaron etiología tóxica, infecciosa y metabólica. La valoración neurológica incluyó un electroencefalograma que mostró disfunción cerebral con enlentecimiento generalizado de la actividad, sin morfología epileptiforme, así como una tomografía computada simple y contrastada que mostró un infarto insular. Dos días después concluyó el embarazo por aborto espontáneo y el estudio histológico de la placenta mostró múltiples trombos, hemorragia intervellosa extensa y áreas de infarto isquémico (Fig. 1). En este contexto se realizó una resonancia magnética de cráneo, en la que se documentaron múltiples lesiones hiperintensas periventriculares y subcorticales (Fig. 2). De acuerdo con los resultados de imagen y determinantes serológicos se formula el diagnóstico de: 1) LES, con los criterios de clasificación SLICC 2012 de linfocitopenia, trombocitopenia, hipocomplementemia, 


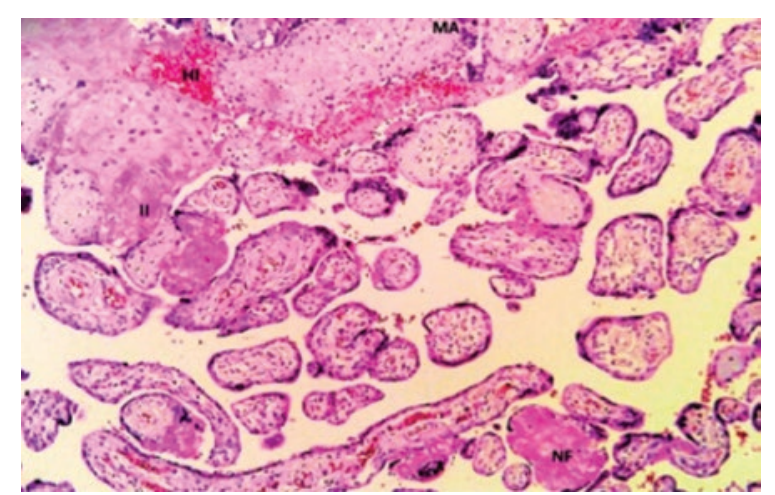

Figura 1. Corte de placenta con vellosidades correspondientes al primer trimestre de la gestación. Tinción de hematoxilina-eosina. Evidencia de infiltrado polimorfonuclear, MA, HI, NF y II. HI: hemorragia intervellosa; II: áreas de infarto isquémico; MA: microabscesos; NF: necrosis fibrinoide.
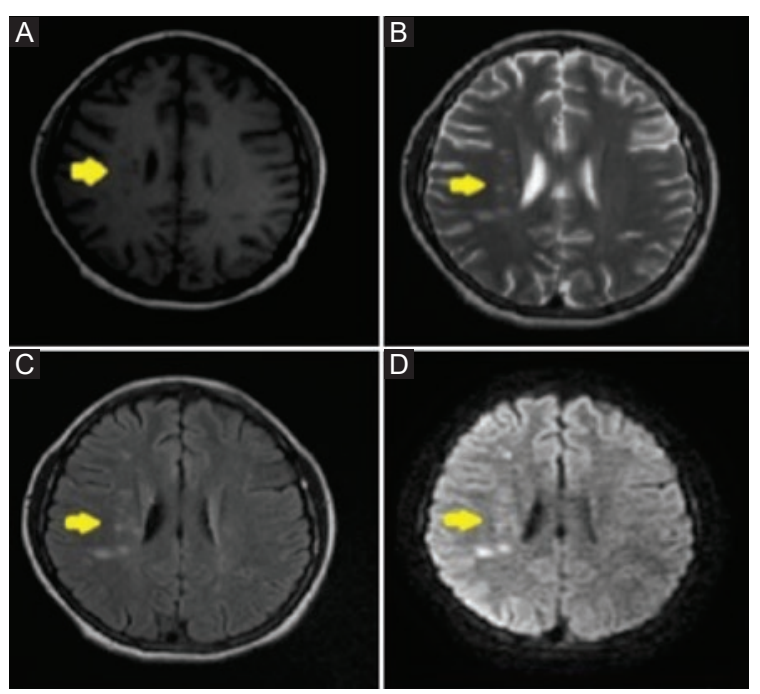

Figura 2. Resonancia magnética, corte axial de encéfalo. A: secuencia $T 1$ con lesiones hipointensas en la región periventricular derecha. B: secuencia T2 con lesiones hiperintensas en la misma localización. C: secuencia FLAIR. D: secuencia difusión.

Coombs directo positivo y anticuerpos antinucleares $1: 1,280$, patrón citoplásmico mitocondrial y SLEDAI $2 \mathrm{~K}$ 35 puntos; 2) SAF según los criterios de clasificación de Sydney de 2006, que incluyen la presencia de un evento isquémico cerebral insular y anticoagulante lúpico positivo; y 3) corea.

Se indicó tratamiento con pulsos de metilprednisolona, ciclofosfamida y anticoagulación, con evolución favorable, y la paciente egresó por mejoría con disminución de los movimientos coreicos. Durante el seguimiento se confirmó la remisión total y sostenida de las manifestaciones. La evaluación mediante el instrumento MEX SLEDAI a los 3 meses del alta hospitalaria reportaron un ítem de 1 punto establecido por la persistencia de linfocitopenia.

\section{Discusión}

La corea ocurre en los primeros años del diagnóstico de LES o como una manifestación inicial de la enfermedad $^{2,5}$, con una edad de inicio de $21 \pm 12$ años, manifestándose con movimientos bilaterales en el 55\% de los casos, y puede asociarse a otros síndromes neuropsiquiátricos como crisis convulsivas, delirio, eventos vasculares cerebrales isquémicos, cambios en la personalidad y psicosis ${ }^{5}$, como ocurrió en esta paciente.

En los reportes de pacientes con corea gravídica publicados hasta ahora se describe clásicamente esta asociación con fiebre reumática; sin embargo, con el advenimiento de la penicilina disminuyó la incidencia de esta enfermedad y en la actualidad las causas identificables son LES y SAF como las más comunes ${ }^{6}$.

Durante el abordaje del caso descrito se descartaron los diagnósticos diferenciales de movimientos coreiformes, como son la enfermedad de Huntington, la fiebre reumática, la encefalitis, la tirotoxicosis, la enfermedad de Wilson y la toxicidad por fármacos (levodopa, fenotiazinas y fenitoína) $)^{7,11}$; la paciente cumplió criterios de clasificación para LES y SAF, por lo que la corea se asoció a estas enfermedades.

\section{Conclusiones}

La corea gravídica primaria o secundaria a LES o SAF es infrecuente. Sin embargo, tras la revisión sistemática de los casos clínicos publicados, los hallazgos descritos en este artículo constituyen el primer caso publicado con coexistencia de LES, SAF y corea como primera manifestación.

Las enfermedades reumáticas como el LES y el SAF deben sospecharse en pacientes con manifestaciones neuropsiquiátricas que inician durante el embarazo. El diagnóstico y el tratamiento oportunos pueden favorecer el desenlace.

\section{Responsabilidades éticas}

Protección de personas y animales. Los autores declaran que para esta investigación no se han realizado experimentos en seres humanos, ni en animales.

Confidencialidad de los datos. Los autores declaran que han seguido los protocolos de su centro de trabajo sobre la publicación de datos de pacientes. 
Derecho a la privacidad y consentimiento informado. Los autores han obtenido el consentimiento informado de los pacientes y/o sujetos referidos en el artículo. Este documento obra en poder del autor de correspondencia.

\section{Conflicto de intereses}

Los autores declaran no tener ningún conflicto de intereses.

\section{Bibliografía}

1. Suárez-Álvarez L, Hughes G, Khamashta M. Manifestaciones neurológicas en el síndrome antifosfolipídico. Med Clin (Barc). 2005;124:630-3.
2. Kivity S, Agmon-Levin N, Zandman-Goddard G, Chapman J, Shoenfeld Y. Neuropsychiatric lupus: a mosaic of clinical presentations. BMC Med. 2015;13:43.

3. Joseph FG, Scolding NJ. Neurolupus. Pract Neurol. 2010;10:4-15

4. Appenzeller S, Costallat LT, Cendes F. Neurolupus. Arch Neurol. 2006;63:458-60.

5. Baizabal-Carvallo JF, Bonnet C, Jankovic J. Movement disorders in systemic lupus erythematosus and the antiphospholipid syndrome. J Neural Transm. 2013;120:1579-89.

6. Palanivelu LM. Chorea gravidarum. J Obstet Gynaecol. 2007;27:310.

7. Robottom BJ, Weiner WJ. Chorea gravidarum. Handb Clin Neurol. 2011;100:231-5.

8. Ichikawa K, Kim RC, Givelber H, Collins GH. Chorea gravidarum. Report of a fatal case with neuropathological observations. Arch Neurol. 1980; 37:429-32.

9. Germes Piña F. Corea gravídica: reporte de un caso. Ginecol Obstet Mex. 2009;77:156-9.

10. Karageyim AY, Kars B, Dansuk R, Aygun E, Unal O. Chorea gravidarum: a case report. J Matern Fetal Neonatal Med. 2002;12:353-4.

11. Pathania M, Upadhyaya S, Singh Lali B, Sharma A. Chorea gravidarum: a rarity in west still haunts pregnant women in the east. BMJ Case Rep. 2013;2013:bcr2012008234. 